This item was submitted to Loughborough's Research Repository by the author.

Items in Figshare are protected by copyright, with all rights reserved, unless otherwise indicated.

\title{
Barriers and benefits of using social networking sites versus face to face meetings for sharing knowledge in professional societies
}

\section{PLEASE CITE THE PUBLISHED VERSION}

http://dx.doi.org/10.1504/IJBIS.2017.083681

\section{PUBLISHER}

(C) Inderscience

\section{VERSION}

AM (Accepted Manuscript)

\section{PUBLISHER STATEMENT}

This work is made available according to the conditions of the Creative Commons Attribution-NonCommercialNoDerivatives 4.0 International (CC BY-NC-ND 4.0) licence. Full details of this licence are available at: https://creativecommons.org/licenses/by-nc-nd/4.0/

\section{LICENCE}

CC BY-NC-ND 4.0

\section{REPOSITORY RECORD}

Al-Busaidi, Kamla A., Gillian Ragsdell, and Ray Dawson. 2019. "Barriers and Benefits of Using Social Networking Sites Versus Face to Face Meetings for Sharing Knowledge in Professional Societies". figshare. https://hdl.handle.net/2134/24917. 


\title{
Barriers and Benefits of Using Social Networking Sites versus Face-to-Face Meetings for Sharing Knowledge in Professional Societies
}

\author{
Kamla Ali Al-Busaidi \\ Department of Information Systems, \\ Sultan Qaboos University, \\ P.O.Box: 20, PC: 123, AlKhod, Oman \\ Fax: + (968) 24414043 \\ E-mail: kamlaa@squ.edu.om \\ Corresponding author

\section{Gillian Ragsdell} \\ Department of Information ManagementSchool of Business and Economics, \\ Loughborough University, \\ Loughborough, Leicestershire, LE11 3TU, UK \\ Fax: +44 (0)1509 223082 \\ E-mail: G.Ragsdell@lboro.ac.uk
}

\section{Ray Dawson}

Department of Computer Science,

Loughborough University,

Loughborough, Leicestershire, LE11 3TU, UK

Fax: +44 (0)1509 223082222679

E-mail: R.J.Dawson@lboro.ac.uk

\begin{abstract}
This study aims to assess the benefits and barriers of social networking sites (SNS) for sharing knowledge in professional societies, compared to face-to-face meetings (F2F). -SNS can be a valuable technology for non-profit organizations. Studies have investigated the barriers and benefits of knowledge sharing in firm-based communities of practice (CoP) or virtual CoP, but not much is known about professional societies' use of public SNS for knowledge sharing. Based on two rounds of a Delphi study, the results revealed the benefits and barriers of F2F meetings compared to the benefits and barriers of SNS for sharing knowledge in professional societies.
\end{abstract}

Keywords: knowledge sharing; professional societies; social networking sites; SNS, face2face meeting; delphi study; knowledge management; knowledge; social media; social networking; knowledge sharing benefits; knowledge sharing challenges. 
Biographical notes: Kamla Ali Al-Busaidi is an Associate Professor of Information Systems at Sultan Qaboos University in Oman. She received her Ph.D. in Management Information Systems from Claremont Graduate University in California. Her research interests include knowledge management systems and learning management systems. She has published articles in several international conference proceedings, book chapters, and journals, including CAIS, Knowledge Management Research and Practice, Behaviour \& Information Technology, international Journal of Knowledge Management and many others. Kamla received a "best paper" award at the 2008 IBIMA conference. She is a reviewer and an editorial member for several conference proceedings and journals.

Gillian Ragsdell is a Senior Lecturer in Knowledge Management and a member of at the Centre for Information Management at Loughborough University's School of Business and Economics. She has published around 90 research outputs including papers in prestigious knowledge management journals such as Knowledge Management Research and Practice $\epsilon$ and Journal of Knowledge Management. She was co-author of the 'Bbest Ppaper' at the 2013 International Conference on Events and was awarded 'Outstanding Paper in the 2015 Emerald Literati Network Awards for Excellence'. Gill is on the editorial review board of International Journal of Socio technology and Knowledge Development, and on the editorial board of Business Information Review. In 2015, Gill was one of 6 UK academics to receive Royal Academy of Engineering funding to support a 12 month industrial secondment as a Knowledge Manager.

Ray Dawson is Professor of Knowledge Management at Loughborough University, UK. He obtained a bachelor's and a masters degree from Nottingham University before entering industry with Plessey Telecommunications in 1977. At the company he developed an interest in software engineering processes and the working methods for information systems development as practiced in industry. Since 1987 he has continued this interest in industrial working methods at Loughborough University, working with companies to improve their software engineering processes and their information and knowledge management systems. A particular interest is Knowledge Management systems

implemeantation as these systems seem to have a particularly poor success record and case studies in this area have revealed some interesting lessons for future system developments.

\section{Introduction}

The objective of this paper is to explore the benefits and the barriers of using social networking sites (SNS) for sharing (dissemination) knowledge in 
communities of practice (CoP) specifically in professional societies context. CoP play a major role on individual, organizational and societal knowledge management. They are considered today as one of the most valuable organizational mechanisms that enable knowledge exchange and the creation of knowledge repository. Even though CoP were originally introduced as informal mechanisms for knowledge exchange by Lave and Wenger in 1991, they are becoming a popular formal mechanism in organizations. CoP foster individual and organizational innovation (Brown and Duguid, 1991; Wenger et al., 2002), and help organizations achieve strategic competitive advantage (Wenger et al., 2002; McDermott, 2003). CoP are also effective tools in handling unstructured problems and to share knowledge outside of the traditional structural boundaries, and are means to develop and maintain long-term organizational memory (Lesser and Storck, 2001). Likewise, CoP in the form of professional societies within a specific nation, are becoming popular and play an important role in the nation's development process. CoP can be applied to civil societies and the principles that apply to businesses, their markets and the broader learning systems in which they participate also apply to the challenges faced by our societies, but beyond the private sector (Wenger et al., 2002). "It is through the social sector that a modern developed society can again create responsible and achieving citizenship, and can again give individuals (and especially knowledge people) a sphere in which they can make a difference in society" (Drucker, 1995, pg.10). CoP, in the form of civil or professional societies, result in several benefits for individuals, their organizations, the domain, and the whole society. For instance, there is a growing interest among practitioners and researchers in the use of socialprofessional networks to develop the health sector (Braithwaite et al., 2009). Bettiol and Sedita (2011) empirically illustrate the role of social community of practice in design in Italy in developing creative industry projects.

Knowledge sharing is a critical knowledge management process in CoP including professional societies. Even though the real benefits of knowledge management areis realized by knowledge application (Scholl et al., 2004), knowledge sharing is the process that enables the creation and accumulation of knowledge. Members' attitudes toward knowledge sharing positively influence intentions to use a virtual community (Gang and Ravichandran, 2015). Consequently, individuals in $\mathrm{CoP}$ learn and benefit from this accumulated knowledge for their individual, organizational and societal problem solving and decision making. Knowledge sharing allows knowledge acquisition, knowledge re-use and knowledge creation (Nonaka and Takeuchi, 1995). Knowledge sharing is the heart of CoP's activities. Without knowledge sharing, learning will not occur; hence the objectives of CoP cannot be achieved. Communicating knowledge and information is one of the main activities of group work (Pinelle and Gutwin, 2003). Gerken Golay et al.(2014) show that sharing knowledge through collaborative learning (such as workshops) improves individuals' (i.e. landowners, foresters, and urban park managers) -learning, decision making, and actions to enhance forest ecosystem functions/services. Such studies indicate the need for CoPs among professionals. Similarly, the Zoological Society achieved 
its mission of advancing animal welfare by widely sharing knowledge, conducting professional training for animal care staff and by organizing discussions in the form of international symposia (Kagan et al., 2015).

The use of information and communication technologies (ICT) to boost knowledge sharing in professional societies is inevitable, especially when professionals are scattered across the country. ICT can improve the capability of knowledge management including knowledge sharing processes (Alavi and Lidner, 1999; Becerra-Fernandez, Gonzalez and Sabherwal, 2004; Davenport and Prusak, 1998). Social networking sites (SNS) can be a potential tool for professional societies as they provide an integrated platform for knowledge exchange. They enable synchronous and asynchronous individual and group knowledge sharing. Internet and groupware technologies create a platform to support knowledge sharing process. The use of technology has led to richer and more meaningful participation in CoP (Wenger et al., 2005). Specifically, groupware technologies may increase individuals' willingness to share knowledge (Maier, 2002).- Organizations are starting to adopt web tools for strategic benefits (Kosalge, 2015). The most important aspect of social media, including social networking sites particularly, is that it provides computermediated communication, collaboration and sharing (Almadhoun et al., 2014).

However, knowledge sharing is a challenging process, and very often it fails because of a lack of people who are willing to share their best practices. It has been estimated that at least $\$ 31.5$ billion are lost per year by Fortune 500 companies because of failing to share knowledge (Babcock, 2004). Moreover, even with its potential benefits, information technologies, such as SNS, may add an extra pressure among senior professionals. Keeping up with new technologies is a major concern in knowledge management (Alavi and Leidner, 1999; Davenport and Prusak, 1998). Little is empirically known about the motivators of knowledge sharing in general (Wang and Noe, 2010) or in CoP (Jeon et al., 2011), and the produced outcomes (Dwivedi et al., 2011). Recognizing the benefits and barriers of knowledge sharing might reveal some insights on the determinants of knowledge sharing in professional societies through SNS.

Accordingly, this study aims to reveal the benefits and barriers of using SNS for sharing knowledge in professional societies. Several studies have investigated knowledge sharing in company based CoP such as Bock et al. (2005), Kankanhalli et al. (2005), Wasko and Faraj (2005) and Jeon et al. (2011). Further, a few studies, such as Lin et al. (2009), Chai and Kim (2012) and Gang and Ravichandran (2015), have investigated knowledge sharing in virtual CoP. However, very limited studies have investigated the knowledge sharing in SNS. One of these studies is by Hung et al. (2010) but is limited to a university context.

Several empirical studies provided some insights of individuals' use of SNS such as Chen (2013), Chang and Zhu (2011), Kim et al. (2010), and Ridings and Gefen (2004). Researchers have been recommending SNS and Web 2.0 technologies for group work in public and non-profit organizations (Huck et al., 2011) but little is known about the use of SNS for sharing knowledge in non- 
profit organizations, such as professional societies' contexts. Professional societies combine formal and informal structure and online and offline activities. Ploderer et al. (2010) indicate that the use of SNS to collaborate between and within amateur, professional, and celebrity groups in the domain of bodybuilding helps individuals to improve their performance in competitions, extend their support network, and gain recognition for their achievements. Thompson et al. (2008) and Rutter and Duncan (2011) have acknowledged the popularity and potential of SNS and social media use by professional networks. Through illustrating examples among medical and healthcare profession, Kind and Evans (2015), indicated that learning "can be considered a social activity", and the use of online social networking and social media fosters learning through knowledge sharing, feedback, and collaboration.

\section{Relevant Literature}

\subsection{Social Networking Sites}

Social Networking Sites (SNS), such as Facebook, LinkedIn, MySpace, Bebo and Badoo, are websites that enable individuals to socially connect, exchange content and collaborate. SNS is defined- as "web-based services that allow individuals to (1) construct a public or semi-public profile within a bounded system, (2) articulate a list of other users with whom they share a connection, and (3) view and traverse their list of connections and those made by others within the system” (Boyed and Ellison, 2008, p.211).

SNS started with Classmates.com, in 1995, followed by SixDegrees.com in 1997 (Boyd and Ellison, 2008; Kim et al., 2010). Facebook, LinkedIn and MySpace are some of the most popular SNS sites. Today, there are thousands of social websites with different features, tools and popularity. Social Media sites, which are defined as sites to share user-created content, started with Fliker (images media site) in 2004 and was followed by YouTube (Videos media site) in 2005. Today, SNS and social media sites are very often combined in the same category by practitioners and researchers as social media sites which also enable the creation of communities. Some of the early main features and tools of SNS are: profiles and status update, groups/friends, wall posts, mail alerts, comments, private messages, chat-rooms, discussion forums and photo-sharing or videosharing capabilities. Some SNSs have blogs and instant messages capabilities. Currently, more features are being added such as mobile usage and games and application as in Facebook, classified and events.

\subsection{Benefits of knowledge sharing and SNS}


The use of SNS to share knowledge in professional societies may result in several benefits for members, knowledge sharing process and the professional societies.

According to knowledge management literature, knowledge sharing may result in the benefits highlighted by the studies of a number of KM researchers (Alavi and Leidner, 1999; Becerra-Fernandez et al., 2004; Lee and Choi, 2003). These benefits can be classified as employee benefits (such as productivity, learning, adaptability, innovation and job satisfaction), business process benefits (such as improved efficiency, effectiveness, innovation and communication), product benefits (such as improved products/services quality, new value-added features to products/services, new value-added products/services and new knowledge-based products/services), customer benefits (including improved customer satisfaction, improved customer services, improved customer loyalty and improved customer-company communication), financial benefits (such as increased sales, decreased cost and increased profitability and ROI) and intangible benefits (including improved leadership, improved competitive advantage and larger market share).

Researchers have identified different reasons for using SNS. According- to Ridings and Gefen (2004), people may use it for seeking information, social support, friendship, and recreation, whereas Wellman and Gulia (1999) indicated that people use SNS for obtaining- information, social/emotional support, and a sense of belonging, encouragement and companionship. Chang and Zhu (2011), Kim et al. (2011) and Ji et al. (2011) created a comprehensive categorization of these uses based on the literature, and seeking information and finding experts are among these uses. Almadhoun et al. (2014) indicated that the most important aspects of social media, including social networking sites, are supporting computer-mediated communication, collaboration and sharing. Thus, SNS are no

| longer just for networking and socialization with friends, but they are recognized as a platform for information (knowledge) exchange.

SNS can be used by organizations to reach customers (Lorenzo-Romero et al., 2011) and improve their relationship with customers (Su et al., 2015). Small and Medium Enterprises (SME) even use social media for e-commerce (Abed et al., 2015). In addition, SNS provide organizations a useful source of identifying potential employees (DeKay, 2009), and provide their employees' opportunities for online learning and education and improved interactivity. For internal employees, SNS can be used to support cooperative work (Rooksby and Sommerville, 2011), to build stronger bonds with their weak ties (Skeels and Grudin 2009), social connections and gatherings (DiMicco and Millen, 2007), and even for emergency notification (Han et al., 2015). The growth of SNS signifies a move in the organization of online communities (Boyd and Ellison, 2008). Business benefits that result from adopting social media are improved employee engagement, improved internal communication, and improved development of internal communities (Rees and Hopkins, 2007).

\subsection{Barriers of knowledge sharing and SNS}


A number of quantitative and qualitative empirical studies have investigated the determinants or barriers of knowledge sharing behavior in a company context, such as -Bock et al.(2005), Kankanhalli- et al (2005), Wasko and Faraj(2005), Cabrera(2006), Jeon et al. (2011), Chen et al.(2012) and Al-Busaidi et al.(2010). Chen et al. (2012) found that self-efficacy and organizational climate were critical factors on knowledge sharing. Bock et al. (2005) found that attitude toward knowledge sharing, subjective norms and organizational climate affect individuals' intentions to share knowledge, whereas anticipated extrinsic rewards have a negative effect on individuals' knowledge-sharing attitudes. Kankanhalli et al. (2005) found that knowledge self-efficacy and enjoyment in helping others significantly impact electronic knowledge repository (EKR) usage by knowledge contributors, and contextual factors (generalized trust, pro-sharing norms, and identification) moderate the impact of codification effort, reciprocity, and organizational reward on EKR usage, respectively. Wasko and Faraj (2005) found that individuals contribute their knowledge when they believe it enhances their professional reputations, they have the experience to share, and when they are structurally embedded in the network. Cabrera (2006) found that selfefficacy, openness to experience, perceived support from colleagues and supervisors, organizational commitment, job autonomy, perceptions about the availability and system quality and perceptions of rewards significantly determine knowledge sharing behavior. Al-Busaidi et al. (2010) found that individuals' knowledge sharing behavior to KMS was motivated by organizational-culture dimensions (such as management support and rewards policy) and the system technical characteristics (such as system quality). Jeon et al. (2011) found that the enablers of attitude toward knowledge sharing in CoP are image, reciprocity, enjoyment in helping others and the need for affiliation. The enablers of intention to share knowledge in CoP are perceived behavioral control, subjective norms along with attitude and the enablers of knowledge sharing behavior in $\mathrm{CoP}$ are intention to share knowledge and facilitating conditions. A recent theoretical framework on knowledge sharing behavior by Wang and Noe (2010), categorizes enablers of knowledge sharing in five areas: organizational context, interpersonal and team characteristics, cultural characteristics, individual characteristics, and motivational factors. However, this theoretical framework lacks attention to the technological aspects of knowledge sharing.

- In virtual communities, Gang and Ravichandran (2015) found that the determinants of attitudes toward knowledge exchange includes trust among participants and the relevance of the community to participants' jobs; in addition they found that attitudes toward knowledge sharing positively influence intentions to use a virtual community. Also, -Hidayanto et al. (2015) categorized influential factors of knowledge sharing behavior as individual factors, technological factors and contextual factors, and found information quality, the norm of reciprocity, the expectation outcomes, the enjoyment in helping others and the interpersonal trust are the significant influential factors on knowledge 
sharing behaviour. Trust is also important for successful online interactions and acts as an important role for many web-based companies (Ayyash et al., 2012)

Based on the SNS literature, there are some recent concerns of privacy, personal identity and security and information overload with SNS, which might

| limit their adoption by individuals and organizations.- Brandtzæg et al. (2010) indicated that public and private information privacy and information overload (oversharing) is a major concern about SNS designs. Users are overloaded with information from other users in their social networks and from the classifieds and ads published by SNS. Security and privacy are still a major concern on SNS (Al-Busaidi, 2014; Almadhoun et al., 2014) and social media (Saleh Zolait et al, 2014). Several risks may result from the deficit of privacy and security in SNS. Some of these risks are identity theft, hacking, leaking of information and loss of productivity. The risk from identity theft, in SNS, results from insufficient system security controls and practices and fraudulent emails and messages (Hoy and Milne, 2010). Insufficient security controls also may result in a hacking risk. Also, SNS use might result in privacy threats such as location privacy and absence privacy, which refers to users' presence or absence, respectively, of a specific location at a given period of time (Freni et al., 2010; Zhan et al., 2011). In addition, information overload, which participants get from posted messages and data by social networkers or the SNS sites themselves, might also impact individuals' time and consequently productivity (Marakas, 2003). Because of this concern, some organizations even block access to social networking sites as they believe social networking is a "productivity killer" (Brodkin, 2008). Furthermore, employees and their organizations might be threatened by legal risks and liabilities with every click they make on SNS. For instance, in an academic context, Henderson (2010) illustrated serious misunderstood legal risks with students' use of social networking sites.

\section{$3 \quad$ Research Objectives \& Questions}

As indicated in the above literature, sharing knowledge and information among individuals in organizations including professional society adds great value to individuals, organization and the society (Alavi and Leidner, 1999; BecerraFernandez et al., 2004; Lee and Choi, 2003). Individual benefits may include improved learning, adaptability, innovation, job satisfaction and strengthen | relationships. Organizational benefits may include improved efficiency, effectiveness and innovation in business processes and services, which may consequently be linked to financial benefits and market benefits. The utilized organizational mechanism or technology for sharing knowledge among members may positively facilitate the knowledge sharing process, or may encounter challenges. These challenges can be related to individual (e.g. availability and attitude), organizational (e.g. management support and rewards), and technical issues (e.g. speed) (Bock et al., 2005; Kankanhalli -et al., 2005; Wasko and Faraj, 
Title

2005; Cabrera, 2006; Al-Busaidi et al., 2010; Jeon et al., 2011; Chen et al. 2012).

- Knowledge sharing is a core process in professional society as the aim of any professional society is to share knowledge among professionals in a specific domain to benefit the domain and the society (Gerken Golay et al., 2014; Kagan et al., 2015; Kind and Evans, 2015). One of the popular traditional mechanisms for sharing knowledge is a face-to-face meeting. The utilization of communication and collaboration technologies (groupware) adds value to individuals and organizations as it overcomes the time and location limitations of the traditional mechanisms (Marakas, 2003; Dalkir, 2011).

- The literature indicates that social networking sites (SNS) can be a promising tool for non-profit organizations (Huck et al., 2011), including professional societies (Thompson et al., 2008; Rutter and Duncan, 2011), as they provide a free integrated platform for knowledge exchange. The SNS provides computermediated communication, collaboration and sharing (Almadhoun et al., 2014). However, technology can add also some barriers to the knowledge sharing process. In addition, due to its public nature, the use of SNS may be confronted by some individual, technical and organizational issues. Even though there are several empirical research studies on the individuals' use of SNS, such as Chen (2013), Chang and Zhu (2011), Kim et al. (2010), and Ridings and Gefen (2004), the research on its use in professional societies is very limited.

- Consequently, this study aims to shed light on the benefits and barriers of using public social networking sites (SNS) for sharing knowledge in professional societies. This study aims to explore these two research objectives by making a comparison between the use of SNS and Face-to-Face meeting (as the most popular mechanism) for knowledge sharing as illustrated by Figure 1. Thus, four open-ended questions were developed to compare the barriers and benefits of using SNS versus Face-to-Face meetings for sharing knowledge in professional societies. These research questions are as follows:

1. What are the BENEFITS (e.g. individual and organizational) of using a social networking site for sharing knowledge with other members in your professional society?

2. What are the BENEFITS (e.g. individual and organizational) of using a face-to-face meeting for sharing knowledge with other members in your professional society?

3. What are the BARRIERS (e.g. individual, organizational and technical) of using social networking sites for sharing knowledge with other members in your professional society?

4. What are the BARRIERS (e.g. individual, organizational and technical) of using a face-to-face meeting for sharing knowledge with other members in your professional society? 


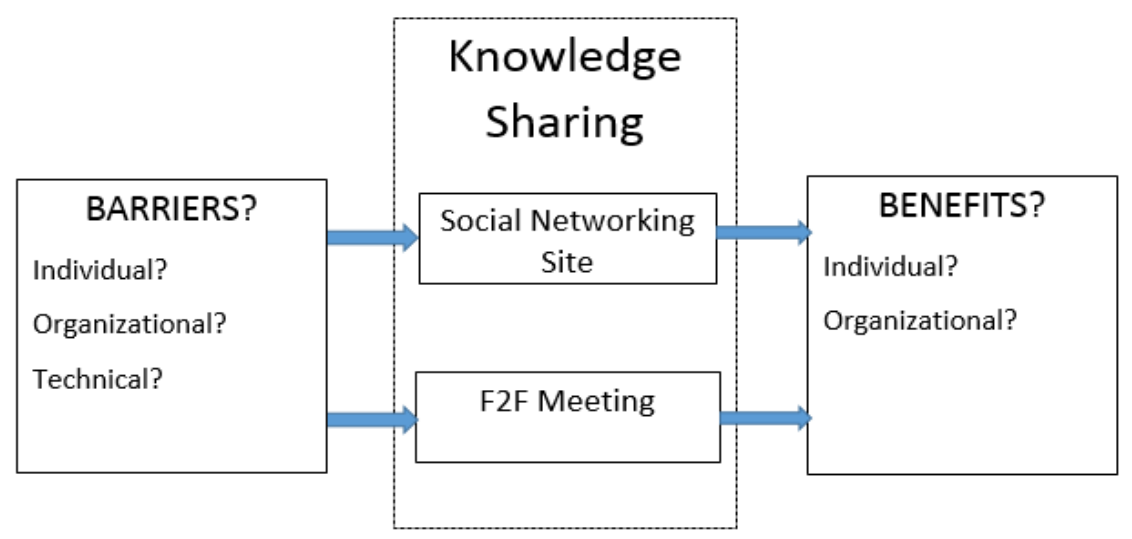

\section{Methodology}

\subsection{The Delphi Technique}

This study aims to identify the benefits and barriers of using SNS for workgroups in public organizations through the Delphi technique. The Delphi technique improves the validity of the results as the iterative process of the technique aims to reach consensus among participating experts on the investigated issues. The Delphi technique is a survey instrument that is used to collect initial input from members who are experts in the investigated subject. The Delphi technique is considered to produce the most reliable consensus of a group of experts, through a series of in-depth questionnaires, combined with controlled feedback (Dalkey and Helmer, 1963). The method was initially developed by the US Defense Department in the 1950s (Dalkey and Helmer, 1963). At the beginning, the majority of Delphi studies were for pure forecasting (short- and long-range forecasts), but it has been used now for concept/framework development (Okoli and Pawlowski, 2004). One of the most frequently adopted designs is the one developed by Schmidt (1997), which consists of brainstorming, selecting and ranking. Another popular version was 
created by Daniel and White (2005), which consists of generating ideas and issues, eliciting agreement and gaining consensus.

\subsection{Expert Selection and Profile}

In a Delphi study, participants are not selected randomly but they are selected and identified based on their knowledge of the investigated subject area (Okoli and Pawlowski, 2004). The size requirements of a Delphi panel can vary from small to large (Linstone and Turoff, 1975).

This study aims to assess benefits and barriers of using SNS for sharing knowledge in professional societies. An email invitation was sent to six professional societies in Oman to invite their members who have good knowledge of SNS to participate in the study through an online-based questionnaire. Three societies showed a positive response, but no information was provided by the societies on how many members were invited. Ten participants, however, participated in the Round 1 of the study and agreed to participate in the second round of the Delphi technique. Ten participants is acceptable for a Delphi study as was found in several studies, including Fischer's study (1981), reported by Rowe and Wright's (1999) literature review on the Delphi technique. For Round 2, these ten participants were invited to participate.

$-50 \%$ of the participants were male and $50 \%$ were female. $40 \%$ of participants had a Bachelor Degree, 30\% of them had Master Degree and 30\% of them had $\mathrm{PhD}$. Only $20 \%$ of participants had a year or less work experience, $10 \%$ of participants had between 2 to 3 years, $50 \%$ of participants had between 4 to 13 years work experience and $20 \%$ of participants had at least 20 years work experience. $90 \%$ of them had been members for two to five years and $10 \%$ of them had been a member for 13 years. $80 \%$ of them indicated they used Facebook, the rest used Badoo. 80\% of them supported the use of SNS for professional societies, and $80 \%$ of them considered it successful for professional societies.

\subsection{Data Collection}

The first round (Round 1) of the Delphi technique is a brainstorming process, where participating domain experts are asked to generate and identify ideas and issues through a questionnaire instrument to ensure anonymity (Okoli and Pawlowski, 2004; Schmidt,1997). The conventional way of conducting Round 1 of a Delphi study is through a "blank sheet" approach in which participants are asked to generate ideas for the research questions (Okoli and Pawlowski, 2004; Schmidt, 1997). The questionnaire utilized in this study included demographic 
questions such as (gender, age, qualification, work experience, etc.) along with open ended research questions. The questionnaire also included measurements, based on 5-points Likert-scale, that assess the usefulness of SNS tools for sharing declarative (Know-what) and procedural knowledge (Know-how) in professional societies.

Round 2 of the Delphi technique is the eliciting agreement round (Daniel and White, 2005). The objective of this round is to identify the top items (identified in the round) that participants agreed with (Daniel and White, 2005). The whole idea of this round to narrow down the list of items identified in Round 1 by participants to a reasonable and manageable number of items as recommended by Schmidt (1997). A 5-point Likert scale is used to assess participants' agreement or disagreements with the identified items in Round 1.

Round 3 is the ranking stage, where participants are asked to rank the items according to their significance (Schmidt, 1997). Unfortunately, this stage was not conducted because of low participation. Thus, ranking is assigned according to the items average score in Round 2.

\section{Analysis \& Findings}

\subsection{Analysis}

Round 1 of the Delphi technique is typically analyzed by consolidating the lists of generated ideas and grouping them into categories. Content analysis is used to group the qualitative comments elicited in Round 1 of the Delphi study according to similar themes (Hussey and Hussey, 1997). Frequency and frequency percentage is used to summarize issues identified by respondents in the openended questions. Round 2 of the Delphi study was analyzed by reporting the average scale point of the 5 -points Likert scale (1 = strongly disagree; 2 = disagree; 3 = neutral; 4 = agree, and 5 = strongly agree).

Since Round 3, the ranking stage, was not conducted, the final ranking of the items (benefits or barriers) was assigned according to their average scale of Round 2.

\subsection{Usefulness of SNS Tools}

Table 1 illustrates the usefulness of SNS tools for sharing declarative knowledge and procedural knowledge. The tools were assessed based on 5-points scale (1=Very Useless, 2= Useless, 3 = Neither Useful nor Useless, 4= Useful, 5= Very Useful). As illustrated in the table, the top five useful tools for sharing declarative (know-what) knowledge within the professional societies were email (average $=4.70$ ), text document-sharing (4.33), instant messages (4.20), photosharing (4.10), video sharing (4.10) and video-conferencing (4.10); whereas the top five useful tools for sharing procedural (know-how) knowledge within the professional societies were video-conferencing (average $=4.80$ ), video sharing 
(4.44), photo-sharing (4.40), email (4.20) and instant messages (4.10). The results implied that sharing procedural knowledge requires richer tools (videobased tools); whereas lean tools (text-based tools) were more useful to share declarative knowledge (know-what).

Table 1. Usefulness of SNS Tools

\begin{tabular}{|c|c|c|c|c|c|c|c|}
\hline $\begin{array}{l}\text { Usefulness of } \\
\text { SNS tools for } \\
\text { sharing } \\
\text { Know-What }\end{array}$ & $\begin{array}{l}\text { Average } \\
\text {-scale }\end{array}$ & Useful & $\begin{array}{l}\text { Very } \\
\text { Useful }\end{array}$ & $\begin{array}{l}\text { Usefulness of } \\
\text { SNS tools for } \\
\text { sharing } \\
\text { Know-How }\end{array}$ & $\begin{array}{l}\text { Average } \\
\text {-scale }\end{array}$ & Useful & $\begin{array}{l}\text { Very } \\
\text { Useful }\end{array}$ \\
\hline Instant messages & 4.20 & $20 \%$ & $50 \%$ & Instant messages & 4.10 & $30 \%$ & $50 \%$ \\
\hline Email & 4.70 & $30 \%$ & $70 \%$ & Email & 4.20 & $50 \%$ & $40 \%$ \\
\hline Blogs & 3.30 & $50 \%$ & $0 \%$ & Blogs & 3.10 & $10 \%$ & $10 \%$ \\
\hline $\begin{array}{l}\text { Discussion } \\
\text { forums }\end{array}$ & 3.67 & $0 \%$ & $40 \%$ & $\begin{array}{l}\text { Discussion } \\
\text { forums }\end{array}$ & 3.80 & $30 \%$ & $30 \%$ \\
\hline Chat rooms & 3.90 & $40 \%$ & $30 \%$ & Chat rooms & 4.00 & $20 \%$ & $40 \%$ \\
\hline $\begin{array}{l}\text { Text document- } \\
\text { sharing }\end{array}$ & 4.33 & $30 \%$ & $50 \%$ & $\begin{array}{l}\text { Text document- } \\
\text { sharing }\end{array}$ & 3.70 & $40 \%$ & $30 \%$ \\
\hline Photo-sharing & 4.10 & $20 \%$ & $50 \%$ & Photo-sharing & 4.40 & $30 \%$ & $60 \%$ \\
\hline Video sharing & 4.10 & $0 \%$ & $60 \%$ & Video sharing & 4.44 & $20 \%$ & $60 \%$ \\
\hline Wikis & 3.80 & $20 \%$ & $40 \%$ & Wikis & 3.89 & $30 \%$ & $30 \%$ \\
\hline Teleconferencing & 3.80 & $20 \%$ & $40 \%$ & Teleconferencing & 3.89 & $20 \%$ & $40 \%$ \\
\hline $\begin{array}{l}\text { Video- } \\
\text { conferencing }\end{array}$ & 4.10 & $10 \%$ & $60 \%$ & $\begin{array}{l}\text { Video- } \\
\text { conferencing }\end{array}$ & 4.80 & $0 \%$ & $90 \%$ \\
\hline $\begin{array}{l}\text { Overall social } \\
\text { networking sites }\end{array}$ & 4.67 & $30 \%$ & $60 \%$ & $\begin{array}{l}\text { Overall social } \\
\text { networking sites }\end{array}$ & 4.25 & $20 \%$ & $40 \%$ \\
\hline
\end{tabular}

\subsection{Benefits of SNS Vs. F2F Meetings for Professional Societies}

Table 2 illustrates the benefits of using social networking sites (SNS) for sharing knowledge in professional societies compared to Face-to-Face meetings (F2F). In Round 1, the participating professionals identified 20 benefits results from using SNS. Table 2 also illustrates the average score of Round 2 out of the 5-points Likert scale. The results indicated that the top 10 benefits of using SNS for sharing knowledge in professional societies based on average score of Round 2 were related to the improved awareness of society news (average score $=4.2$ ), the improved information manipulation and editing (4.2), the saved time (4.2), the improved reach (4.2), the continuous sharing of knowledge (4.2), the 
capability to accommodate all members (4.2), the accessibility of information anytime and many times (4.2), the convenient way of communication (4.2), the improved professional society's knowledge management (4.2), and the savedpaper cost (4.2).

Table 2. Benefits of SNS versus F2F Meetings

\begin{tabular}{|c|c|c|c|c|c|c|}
\hline Rank & SNS Benefits & $\begin{array}{l}\text { R2- } \\
\text { Avg }\end{array}$ & $\begin{array}{l}\text { R1 } \\
\text { Freq\% }\end{array}$ & F2F Benefits & $\begin{array}{l}\text { R2- } \\
\text { Avg }\end{array}$ & $\begin{array}{l}\text { R1 } \\
\text { Freq\% }\end{array}$ \\
\hline 1 & $\begin{array}{l}\text { Become aware about the } \\
\text { society events, news and } \\
\text { services }\end{array}$ & 4.4 & $20 \%$ & $\begin{array}{l}\text { Ability to } \\
\text { develop/strengthen personal } \\
\text { relationship with others }\end{array}$ & 4.2 & $20 \%$ \\
\hline 2 & $\begin{array}{l}\text { Able to manipulate (edit and } \\
\text { search) information }\end{array}$ & 4.2 & $10 \%$ & It has a good social impact & 4.2 & $10 \%$ \\
\hline 3 & $\begin{array}{l}\text { It saves time: fast knowledge } \\
\text { and information sharing }\end{array}$ & 4.2 & $40 \%$ & $\begin{array}{l}\text { We can have more } \\
\text { discussions and more } \\
\text { knowledge sharing }\end{array}$ & 4.2 & $10 \%$ \\
\hline 4 & It can reach all people & 4.2 & $10 \%$ & An opportunity to get out & 4 & $10 \%$ \\
\hline 5 & $\begin{array}{l}\text { Continuous sharing of } \\
\text { thoughts and knowledge. }\end{array}$ & 4.2 & $10 \%$ & $\begin{array}{l}\text { Easy to explain and to be } \\
\text { understood }\end{array}$ & 4 & $10 \%$ \\
\hline 6 & Can accommodate all of us & 4.2 & $10 \%$ & Improve the performance & 3.8 & $10 \%$ \\
\hline 7 & $\begin{array}{l}\text { Information can be accessed } \\
\text { any time and recalled many } \\
\text { times }\end{array}$ & 4.2 & $50 \%$ & $\begin{array}{l}\text { Individuals can discuss } \\
\text { things in more details than } \\
\text { using social network. }\end{array}$ & 3.8 & $10 \%$ \\
\hline 8 & $\begin{array}{l}\text { Convenient way of } \\
\text { communication }\end{array}$ & 4.2 & $10 \%$ & $\begin{array}{l}\text { Confident to get immediate } \\
\text { replay }\end{array}$ & 3.8 & $10 \%$ \\
\hline 9 & $\begin{array}{l}\text { Improve society's knowledge } \\
\text { management }\end{array}$ & 4.2 & $10 \%$ & $\begin{array}{l}\text { Improve the level of } \\
\text { understanding because of } \\
\text { body language and facial } \\
\text { expression }\end{array}$ & 3.6 & $10 \%$ \\
\hline 10 & Saving paper & 4.2 & $10 \%$ & $\begin{array}{l}\text { More secure and } \\
\text { confidential }\end{array}$ & 3.4 & $10 \%$ \\
\hline 11 & $\begin{array}{l}\text { Easy to use: communicate, } \\
\text { check and share/disseminate } \\
\text { information }\end{array}$ & 4.0 & $40 \%$ & $\begin{array}{l}\text { More trustworthy than } \\
\text { online }\end{array}$ & 3.2 & $10 \%$ \\
\hline 12 & $\begin{array}{l}\text { Get closure to friends and } \\
\text { colleagues }\end{array}$ & 4.0 & $10 \%$ & Saving time & 3.2 & $20 \%$ \\
\hline 13 & $\begin{array}{l}\text { Flexibility in } \\
\text { information/activity sharing }\end{array}$ & 3.8 & $10 \%$ & $\begin{array}{l}\text { Helpful for urgent } \\
\text { discussion and decision } \\
\text { making }\end{array}$ & 3.2 & $10 \%$ \\
\hline 14 & $\begin{array}{l}\text { A good tool to backup and } \\
\text { restore information }\end{array}$ & 3.8 & $10 \%$ & $\begin{array}{l}\text { Easy to share common } \\
\text { problems }\end{array}$ & 3.2 & $20 \%$ \\
\hline 15 & $\begin{array}{l}\text { Can use the service in mobile } \\
\text { for quick access and } \\
\text { response }\end{array}$ & 3.8 & $10 \%$ & $\begin{array}{l}\text { Physical presence improves } \\
\text { voluntarily knowledge } \\
\text { sharing }\end{array}$ & 2.8 & $10 \%$ \\
\hline 16 & $\begin{array}{l}\text { Place independent: Available } \\
\text { anywhere }\end{array}$ & 3.6 & $20 \%$ & $\begin{array}{l}\text { Make sure the information } \\
\text { has been shared between } \\
\text { members. }\end{array}$ & 2.6 & $10 \%$ \\
\hline 17 & Ensure large number can & 3.6 & $20 \%$ & & & \\
\hline
\end{tabular}


benefit from the shared

knowledge

18 Improve updating our

scientific knowledge

19 Instantaneous

20 Almost costless

inexpensive

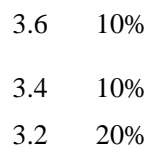

On the other hand, as indicated in Table 2, the participating professionals identified 16 benefits for the use of F2F meetings for sharing knowledge in professional societies. The results revealed, based on Round 2 average score, that the top 10 benefits of using F2F meeting are the ability to develop/strengthen personal relationships with others (average score $=4.2$ ), the good social impact (4.2), the improved discussions and improved knowledge sharing (4.2), the opportunity to get out (4), the easiness to explain and be understood (4), the improved performance (3.8), the improved detailed discussions (3.8), the confidence of getting an immediate reply (3.8), the improved level of understanding because of body language and facial expression (3.6) and the improved security and confidentiality (3.4).

Thus, the benefits of using F2F meetings were related to individual benefits (opportunity to get out and improved learning and understandability), organizational knowledge sharing process benefits (improved social impacts and relationships, richness and security, trust, clarity, responsiveness and discussions) whereas, the benefits of using SNS were related to individual benefits (improved learning: awareness), organizational knowledge sharing process benefits (improved knowledge manipulation and management, reachability, accessibility, convenience, members involvement and participation) and organizational efficiency benefits (saving papers). In conclusion, the benefits of F2F meetings were related to improved social impact and relationships, the richness, trust, confidence and security of sharing knowledge; whereas, the benefits of SNS were related to improved reachability, accessibility, efficiency and knowledge manipulation.

\subsection{Barriers of SNS vs. F2F Meetings for Professional Societies}

Table 3 illustrates the barriers of using social networking sites (SNS) for sharing knowledge in professional societies compared to Face-to-Face meetings (F2F). In Round 1, the participating professionals identified 23 barriers for sharing knowledge through SNS. Table 3 also illustrates the average score of Round 2 from the 5-point Likert scale. The results indicate that the top 10 barriers of using SNS for sharing knowledge in professional societies based on the average score of Round 2 were the lack of awareness of SNS benefit (AVG $=4.6$ ), the lack of individuals' interest (4.4), the individuals' resistance to voluntarily share knowledge through SNS (4.2), the lack of dedicated skillful members at the society to handle SNS sites (4.2), the low Internet connection and speed (4.0), the 
Author

lack of society support and approval of SNS (4.0), the lack of peer support (4.0), the unavailability of technical support (3.8), the importance of face-to-face culture in Oman (3.8) and the lack of Internet skills (3.8).

Table 3. Barriers of SNS versus F2F Meetings

\begin{tabular}{|c|c|c|c|c|c|c|}
\hline Rank & SNS Barriers & $\begin{array}{l}\text { R2- } \\
\text { Avg }\end{array}$ & $\begin{array}{l}\text { R1 } \\
\text { Freq } \\
\% \\
\end{array}$ & F2F Barriers & $\begin{array}{l}\text { R2- } \\
\text { Avg }\end{array}$ & $\begin{array}{l}\text { R1 } \\
\text { Freq } \\
\%\end{array}$ \\
\hline 1 & $\begin{array}{l}\text { Individuals are not aware } \\
\text { of the benefit of SNS }\end{array}$ & 4.6 & $10 \%$ & Work load & 4.4 & $10 \%$ \\
\hline 2 & $\begin{array}{l}\text { Some people are simply } \\
\text { not interested }\end{array}$ & 4.4 & $10 \%$ & Limited meeting time & 4.2 & $40 \%$ \\
\hline 3 & $\begin{array}{l}\text { People do not voluntarily } \\
\text { share knowledge through } \\
\text { SNS }\end{array}$ & 4.4 & $10 \%$ & $\begin{array}{l}\text { Meeting time } \\
\text { management }\end{array}$ & 4.2 & $10 \%$ \\
\hline 4 & $\begin{array}{l}\text { Lack of dedicated skillful } \\
\text { member at the society to } \\
\text { handle such sites }\end{array}$ & 4.2 & $10 \%$ & Members absence & 4.2 & $20 \%$ \\
\hline 5 & $\begin{array}{l}\text { Low Internet connections } \\
\text { and speed }\end{array}$ & 4.0 & $30 \%$ & $\begin{array}{l}\text { Lack of organized } \\
\text { meetings }\end{array}$ & 4.2 & $10 \%$ \\
\hline 6 & $\begin{array}{l}\text { Lack of the society } \\
\text { support of SNS }\end{array}$ & 4.0 & $10 \%$ & $\begin{array}{l}\text { Can't share knowledge } \\
\text { effectively }\end{array}$ & 4 & $20 \%$ \\
\hline 7 & Lack of peers support & 4.0 & $10 \%$ & $\begin{array}{l}\text { Inflexibility in sharing } \\
\text { information/knowledge }\end{array}$ & 3.8 & $10 \%$ \\
\hline 8 & $\begin{array}{l}\text { No technical support at } \\
\text { the society }\end{array}$ & 3.8 & $10 \%$ & Finding the right time & 3.6 & $80 \%$ \\
\hline 9 & $\begin{array}{l}\text { Culture of face to face in } \\
\text { Oman is important }\end{array}$ & 3.8 & $10 \%$ & Finding the right place & 3.6 & $50 \%$ \\
\hline 10 & Lack of Internet skills & 3.8 & $10 \%$ & Travel expense & 3.6 & $10 \%$ \\
\hline 11 & $\begin{array}{l}\text { Information cannot be } \\
\text { considered confidential }\end{array}$ & 3.8 & $10 \%$ & $\begin{array}{l}\text { Inflexibility in } \\
\text { using/editing information }\end{array}$ & 3.4 & $10 \%$ \\
\hline 12 & $\begin{array}{l}\text { Internet is not always } \\
\text { available }\end{array}$ & 3.6 & $30 \%$ & Night time difficulty & 3.4 & $10 \%$ \\
\hline 13 & Information screening & 3.6 & $10 \%$ & Takes a lot of effort & 3.4 & $10 \%$ \\
\hline 14 & $\begin{array}{l}\text { Untimely check and delay } \\
\text { in response }\end{array}$ & 3.4 & $20 \%$ & Communication barriers & 3.4 & $10 \%$ \\
\hline 15 & Phobia from Internet piracy & 3.4 & $10 \%$ & Travel distance & 3.4 & $10 \%$ \\
\hline 16 & Lack of computer skills & 3.2 & $10 \%$ & Expensive & 2.8 & $10 \%$ \\
\hline 17 & $\begin{array}{l}\text { Lack of familiarity of SNS } \\
\text { use }\end{array}$ & 3 & $20 \%$ & & & \\
\hline 18 & $\begin{array}{l}\text { Do not trust answering } \\
\text { unknown people's requests }\end{array}$ & 3 & $10 \%$ & & & \\
\hline 19 & Lack of financial support & 2.8 & $10 \%$ & & & \\
\hline
\end{tabular}


Also, as indicated in Table 3, the participating professionals identified 16 barriers for the use of F2F meetings for sharing knowledge in professional societies. The results revealed, based on the Round 2 average score, that the top 10 barriers for sharing knowledge through F2F meetings were the high work load, the limited meeting time, the meeting time management, the members' absence, the lack of organized meetings, the ineffectiveness of this means to share knowledge, the inflexibility in sharing information/knowledge, the difficulty to find the right time, the difficulty to find the right place, and the travel expenses.

Thus, the top barriers of F2F meetings were related to individual barriers (work load, availability and cost), medium technical barriers (the time and location, meetings' management, organization, effectiveness and flexibility for knowledge sharing and manipulation), and organizational barriers (cost). The top barriers of SNS were related to individual barriers (lack of awareness of SNS benefits, interest, voluntary sharing and technical skills), organizational barriers (management support, culture, and peers support, dedicated technical support staff), and technical barriers (internet connection speed and availability and information overload).

\section{Discussions \& Conclusion}

SNS offers several opportunities for group collaboration, knowledge sharing and non-profit organizations. However, some risks might be associated with their use because of their limited security and privacy controls and information overload. This paper reveals the benefits and the barriers of social networking sites (SNS) for sharing knowledge in professional societies compared to face-to-face meetings based on two-rounds of the Delphi technique.

Based on Round 1 of the Delphi technique, 20 benefits for using SNS were identified, and 16 benefits were identified for using F2F meetings. Also, Round 1 revealed 23 barriers for using SNS and 16 barriers for using F2F meetings. Round 1 of the study also revealed that richer multimedia tools (i.e. video conferencing- video-sharing) were more useful than text-based tools for sharing procedural (know-how) knowledge, whereas text-based tools (e.g. email, instant messages, text-documents sharing) were more useful than multimedia tools for sharing declarative knowledge (know-what). 
Based on Round 2, the study indicates that the benefits of F2F meetings were related to improved social impact and relationships, medium richness (body language and facial expression) and security for sharing knowledge; whereas, the benefits of SNS were related to improved reachability, accessibility, efficiency and knowledge manipulation and management. Furthermore, based on Round 2, the study also indicates that the top barriers of F2F meetings were related to individual barriers (work load, availability and cost), medium technical barriers (the time and location, meetings' management, organization, effectiveness and flexibility for knowledge sharing and manipulation), and organizational barriers (cost). The barriers of SNS were related to individual barriers (lack of awareness of SNS benefits, interest, voluntary sharing and technical skills), organizational barriers (management support, culture, and peers support, dedicated technical support staff), and technical barriers (internet connection speed and availability and information overload).

There is no study without limitations. First, even though a panel of ten experts is still acceptable for a Delphi technique, the study could benefit from a larger sample size. In addition, the analysis was based on only two rounds of a Delphi study. Nevertheless, the study provided some theoretical and practical contributions. In terms of theoretical contributions, the study revealed some | preliminary insights intoen the benefits and barriers of using public SNS for professional societies. Even though several empirical studies have been carried out on individuals' use of SNS (such as Chen (2013), Chang and Zhu (2011), Kim et al. (2010), and Ridings and Gefen (2004)), very limited research has been | conducted oin its use by non-profit organizations, such as professional societies. Knowledge sharing is a core process for professional societies' development (Gerken Golay et al., 2014; Kagan et al., 2015; Kind and Evans, 2015), and the use of SNS and social media is becoming very popular in these organizations (Thompson et al., 2008; Rutter and Duncan, 2011). Thus, the results of this study add value to researchers and practitioners using social networking sites in professional societies and group collaboration.

| -The study also provides several practical implications for practitioners (professional societies, individuals and SNS providers). The study has provided some insights into the knowledge in professional societies. These insights can be integrated with the few qualitative studies in this area to develop a better understanding about how professional societies and non-profit organizations can strategically and operationally adopt SNS, and seize their potential for group work and knowledge sharing, and overcome barriers of their use. The results of the study imply that SNS can be utilized by professional societies to complement traditional ways of sharing knowledge (F2F meetings). Traditional F2F meetings, as indicated in the literature, still offer several benefits, such as building trust and reputation, building strong relationships, verifying identity better confidentiality and sharing tacit knowledge (Crowston, 2007; Rhoads, 2010; Salis and Williams, 2010). However, F2F meetings are limited due to location, time and meetings' time management and organization (Graefe and Armstrong, 2011; Rhoads, 2010). 
Similarly this study's results indicate that even though F2F meetings were considered more social and secure, and richer medium than SNS, SNS offers flexibility, accessibility, convenience, and the capability to overcome time and location barriers for sharing knowledge in professional societies, and assist societies in knowledge manipulation and management, which consequently assists in the development of organizational memory. In addition, SNS offers a cost-effective mechanism for sharing knowledge.

However, practitioners should be cautious about the adoption and use of SNS for a critical process as the results indicate that there are several individual barriers (lack of awareness of SNS benefits, interest, voluntary sharing, technical skills), organizational barriers (management support, culture, and peers support, dedicated technical support staff), and technical barriers (internet connection speed and availability and information overload). Trust has significant influence in knowledge sharing behavior (Hidayanto et al., 2015). Thus, professional societies should utilize SNS in a private context to improve the confidentiality of the shared knowledge and professionals, and in a public context, to reach the society members and stakeholders. Professional societies may also develop technological platforms that can integrate other open source or free audio-video conferencing and Web 2.0 collaboration software with SNS to enrich group work at their societies. Professionals at professional societies should be aware of SNS risks as well as their benefits in order to use them in productive and nonthreatening ways. SNS providers should strengthen the design of SNS to create a rich networking and learning environment for individuals and organizations.

Thus, future research could empirically examine the significance of the benefits and barriers of using SNS for sharing knowledge in professional societies or any other context. Future research could also include participants from different types of voluntary and non-profit organizations and from different countries. Future research could also utilize other research methodologies such as social network analysis for this investigation.

\section{References}

Abed, S.S., Dwivedi, Y.K., and Williams, M.D. (2015) 'SMEs' adoption of ecommerce using social media in a Saudi Arabian context: A systematic literature review', International Journal of Business Information Systems, Vol.19, No.2, pp. 159-179.

Alavi, M., and Leidner, D. (1999) 'Knowledge management systems: Issues, challenges, and benefits', Communication of the AIS, Vol. 1, No.7, pp. 1-37.

Al-Busaidi, K.A. (2014) 'SWOT of social networking sites for group work in government organizations: An exploratory Delphi study from IT managers' perspective', VINE, Vol.44, No.1, pp. 121-139. 
Al-Busaidi, K.A., Olfman, L., Ryan, T., and, Leroy, G. (2010) 'Sharing Knowledge to A Knowledge Management System: Examining the motivators and the benefits in an Omani organization', Journal of Organizational Knowledge Management, Vol. 2010, Article ID 325835, 12 pages [Online], http://www.ibimapublishing.com/journals/JOKM/2010/325835/325835.p df (Accessed 1 March 2015).

Almadhoun, N.M., Dominic, P.D.D., and Lai, F.W. (2014) 'Investigation of perceived security, privacy and trust on social networking sites for stakeholder relationships development in malaysian universities', International Journal of Business Information Systems, Vol.15, No.1, pp. $1-21$.

Ayyash, M.M., Ahmad, K. and Singh, D. (2012) 'A hybrid information system model for trust in e-government initiative adoption in public sector organisation', International Journal of Business Information Systems, Vol. 11, No. 2, pp.162-179.

Babcock, P. (2004) 'Shedding light on knowledge management', HR Magazine, Vol.49, No.5, pp.46-50.

Brandtzæg.P, Lüders.M, and Skjetne.J, (2010) 'Too Many Facebook “Friends”? Content Sharing and Sociability versus the Need for Privacy in Social Network Sites', International Journal of Human-Computer Interaction, Vol.26, No.11-12, pp.1006-1030.

Becerra-Fernandez, I., Gonzalez, A and Sabherwal, R. (2004) Knowledge Management, Pearson Education Inc , New Jersey, NJ, USA.

Bettiol, M. and Sedita, S.R. (2011) 'The role of community of practice in developing creative industry projects', International Journal of Project Management, Vol.29, No. 4, pp.468-479.

Bock, G. W., Zmud, R. W., Kim, Y. G., and Lee, J. N. (2005) 'Behavioral intention formation in knowledge sharing: Examining the roles of extrinsic motivators, social-psychological forces, and organizational climate’, MIS Quarterly, Vol.29, No.1, pp.87-111.

Boyd, D. and Ellison, N. (2008) 'Social Network Sites: Definition, History, and Scholarship', Journal of Computer-Mediated Communication, Vol.13, No.1, pp.210-230.

Braithwaite, J., Westbrook, J.I., Ranmuthugala, G., Cunningham, F., Plumb, J., Wiley, J., Ball, D., Huckson, S., Hughes, C., Johnston, B., et al (2009) 'The development, design, testing, refinement, simulation and application of an evaluation framework for communities of practice and social-professional networks’, BMC Health Serv Res, Vol.9, art. No. 162.

Brown, J.S. and Duguid, P. (1991) 'Organizational learning and communities of practice: toward a unified view of working, learning, and innovation', Organization Science, Vol. 2, No.1, pp.40-57.

Cabrera A., Collins W.C., Salgado J.F. (2006) 'Determinants of individual engagement in knowledge sharing', International Journal of Human Resource Management, Vol.17, No.2 , pp. 245-264. 
Chang, Y.P. and Zhu, D.H. (2011) 'Understanding social networking sites adoption in China: A comparison of pre-adoption and post-adoption', Computers in Human Behavior, Vol.27, No.5, pp.1840-1848.

Chen, R. (2013) 'Member use of social networking sites - an empirical examination', Decision Support Systems, Vol. 54, No. 3, pp. 1219-1227

Chen, S-S, Chuang, Y-W., Chen, P-Y. (2012) 'Behavioral intention formation in knowledge sharing: Examining the roles of KMS quality, KMS selfefficacy, and organizational climate', Knowledge-Based Systems, Vol. 31, pp. 106-118.

Crowston, K., Howison, J., Masango, C., and Eseryel, U. Y. (2007) 'The role of face-to-face meetings in technology-supported self-organizing distributed teams', IEEE Transactions on Professional Communication, Vol. 50, No.3, pp. 185-203.

Dalkey, N., and Helmer, O. (1962-63) 'An experimental application of the Delphi method to the use of experts', Management Science, Vol.9, No.3, pp.458-467.

Daniel, E.M. and White, A.N. (2005) 'The future of inter-organisational system linkages: findings of an international Delphi study’, European Journal of Information Systems, Vol.14, No.2, pp.188-203.

Dwivedi, Y. K., Venkitachalam, K., Sharif, A M., Al-Karaghouli, W. and Weerakkody, V. (2011) 'Research Trends in Knowledge Management: Analyzing the Past and Predicting the Future', Information Systems Management, Vol.28, No.1, pp.43-56.

Drucker, P. (1995) Managing a Time of Great Change, Truman Talley Books, New York.

Finne, T. (2000) 'Information systems risk management: Key concepts and business processes', Computers and Security, Vol.19, No.3, pp. 234-242

Fischer, G. W. (1981) 'When oracles fail - a comparison of four procedures for aggregating subjective probability forecasts', Organizational Behavior and Human Performance, Vol.28, No.1, pp.96-110.

Gang, K. and Ravichandran, T. (2015) 'Exploring the determinants of knowledge exchange in virtual communities', IEEE Transactions on Engineering Management, Vol. 62, No. 1, pp. 89-99.

Gerken Golay, M.E., Bice, P.M. and Thompson, J.R. (2014) 'Collaborative learning about forest understory restoration and management: Identifying goals and sharing knowledge', Journal of Forestry, Vol. 112, No. 4, pp. 327-336.

Graefe, A. and Armstrong, J. S. (2011) 'Comparing face-to-face meetings, nominal groups, Delphi and prediction markets on an estimation task,' International Journal of Forecasting, Vol. 27, No.1, pp. 183-195.

Han, W., Ada, S., Sharman, R., Gray, R.H., and Simha, A. (2015) 'Factors impacting the adoption of social network sites for emergency notification purposes in universities', International Journal of Business Information Systems, Vol. 18, No.1, pp. 85-106. 
Heisig, P. (2009) 'Harmonisation of Knowledge Management - Comparing 160 KM Frameworks around the Globe', Journal of Knowledge Management, Vol.13, No.4, pp.4-31.

Hidayanto, A.N., Limupa, A., Junus, K.M., and Budi, N.F. (2015) 'Investigating knowledge sharing behaviour on virtual community members: Integration of technological, individual and contextual factors', International Journal of Business Information Systems, Vol. 19, No.2, pp. 180-204.

Huck, J., Al, R. and Rathi, D. (2011) 'Finding KM solutions for a volunteerbased non-profit organization', VINE: The Journal of Information and Knowledge Management Systems, Vol.41, No.1, pp.26-40.

Hung, S.-Y., Lai, H.-M., and Chou, Y.-C. (2010) 'The determinants of knowledge sharing intention in professional virtual communities: An integrative model', PACIS 2010 - 14th Pacific Asia Conference on Information Systems, pp.1492-1503

Jeon, S-H, Kim, Y-G and Koh, J. (2011) 'An integrative model for knowledge sharing in communities-of-practice', Journal of Knowledge Management, Vol.15, No.2, pp.251-269.

Kagan, R., Carter, S., and Allard, S. (2015) 'A Universal Animal Welfare Framework for Zoos', Journal of Applied Animal Welfare Science, Vol. 18, pp.10.

Kankanhalli, A., Tan, B. C. Y., and Wei, K. K. (2005) 'Contributing knowledge to electronic knowledge repositories: an empirical investigation', MIS Quarterly, Vol.29, No.1, pp.113-143.

Kim, Y. Sohn, D and Choi, S-M. (2011) 'Cultural difference in motivations for using social network sites: A comparative study of American and Korean college students', Computers in Human Behavior, Vol.27, No.1, pp.365372.

Kim, W., Jeong, O-R and Lee, S-W. (2010) 'On Social Website', Information Systems, Vol.35, No. 2, pp.215-236.

Kind, T., and Evans, Y. (2015) 'Social media for lifelong, International Review of Psychiatry’, Vol.27, No.2, pp. 124-132.

Kosalge, P. (2015) 'An empirical examination of Web 2.0 technologies and its readiness for business', International Journal of Business Information Systems, Vol. 19, No.1, pp. 19-40.

Lave, J., and Wenger, E. (1991) Situated learning: Legitimate peripheral participation, Cambridge University Press, Cambridge, U.K.

Lee, H., and Choi, B. (2003) 'Knowledge management enablers, process, and organizational performance: an integrative view and empirical examination', Journal of Management Information Systems, Vol.20, No.1, pp.179-228.

Lesser, E.L. and Storck, J. (2001) 'Communities of practice and organisational performance', IBM Systems Journal, Vol.40, No.4, pp.831-41. 
Lin M.-J.J., Hung S.-W., Chen C.-J. (2009) 'Fostering the determinants of knowledge sharing in professional virtual communities', Computers in Human Behavior, Vol.25, No.4, pp. 929-939.

Linstone, H.A. and Turoff, M. (1975) The Delphi Method: Techniques and Applications, Addison-Wesley, Reading, MA.

Maier, R. (2002) Knowledge Management Systems: Information and communication technologies for knowledge management, Springer, Berlin, Germany.

McDermott, R. (2003) 'Building spontaneity into strategic communities: eight tips to put excitement into management-created CoP', Knowledge Management Review, Vol.5, No.6, pp.28-31.

Nonaka, I. and Takeuchi, H. (1995) The Knowledge Creating Company, Oxford University Press, New York, NY.

Okoli, C. and S. Pawlowski (2004) 'The Delphi method as a research tool: an example, design considerations and applications', Information \& Management, Vol.42, No.1, pp.15-29.

Pinelle, D., Gutwin, C., and Greenberg, S. (2003) 'Task analysis for groupware usability evaluation: Modeling shared-workspace tasks with the mechanics of collaboration', ACM Transactions on Computer-Human Interaction, Vol.10, No.4, pp. 281-311.

Ploderer B., Howard S., Thomas P. (2010) 'Collaboration on social network sites: Amateurs, professionals and celebrities', Computer Supported Cooperative Work: CSCW: An International Journal, Vol.19, No.5, pp. 419-455.

Rhoads, M. (2010) 'Face-to-face and computer-mediated communication: What does theory tell us and what have we learned so far?,' Journal of Planning Literature, Vol. 25, No. 2, pp. 111-122.

Ridings, C. M., and Gefen, D. (2004) 'Virtual community attraction: Why people hang out online', Journal of Computer-Mediated Communication, Vol.10 No.1, pp. 29.

Rowe, G. and Wright, G. (1999) 'The Delphi technique as a forecasting tool: issues and analysis', International Journal of Forecasting, Vol.15, No.4, pp.353-375.

Rutter, P.M., and Duncan, G. (2011) 'Pharmacy professionalism and the digital age', International Journal of Pharmacy Practice, Vol.19, No.6, pp. 431434.

Saleh Zolait, A.H., Al-Anizi, R.R., Ababneh, S., BuAsalli, F., and Butaiba, N. (2014) 'User awareness of social media security: The public sector framework', International Journal of Business Information Systems, Vol.17, No.3, pp. 261-282.

Salis, S., and Williams, A. M. (2010) 'Knowledge Sharing through Face-to-Face Communication and Labour Productivity: Evidence from British Workplaces', British Journal of Industrial Relations, Vol. 48, No. 2, pp. 436-459. 
Schmidt, R.C. (1997) 'Managing Delphi surveys using nonparametric statistical techniques', Decision Sciences, Vol.28, No.3, pp. 763-774.

Scholl, W., Konig, C., Meyer, B., and Heisig, p. (2004) 'The Future of Knowledge Management: An international Delphi study', Journal of Knowledge Management, Vol.8, No.2, pp. 19-35.

Su, N., John Mariadoss, B., Reynolds, D. (2015) 'Friendship on social networking sites: Improving relationships between hotel brands and consumers', International Journal of Hospitality Management, Vol. 51, articleNo. 1675, pp. 76-86.

Thompson, L.A., Dawson, K., Ferdig, R., Black, E.W., Boyer, J., Coutts, J., and Black, N.P. (2008) 'The intersection of online social networking with medical professionalism', Journal of General Internal Medicine, Vol.23 No.7 , pp. 954-957.

Wang, S. and Noe, R.A. (2010) 'Knowledge sharing: A review and directions for future research’, Human Resource Management Review, Vol.20, No.2, pp.115-131.

Wasko, M.M. and Faraj, S. (2005) 'Why should I share? Examining social capital and knowledge contribution in electronic networks of practice', MIS Quarterly, Vol. 29, No. 1, pp. 35-57.

Wellman, B., and Gulia, M. (1999) 'Net surfers don’t ride alone'. In B. Wellman (Ed.), Networks in the global village (pp. 72-86). Westview, Boulder, $\mathrm{CO}$.

Wenger, E., McDermott, R. A., and Snyder, W. (2002) Cultivating communities of practice: A guide to managing knowledge, Harvard Business School Press, Boston, MA.

Wenger, E., White, N., Smith, J. D., and Rowe, K. (2005) Technology for communities. In Work, learning and networked: Guide to the implementation and leadership of intentional communities of practice [Online] Retrieved from http://technologyforcommunities.com/CEFRIO_Book_Chapter_v_5.2.pd f (Accessed 1 March 2015). 